\title{
Basic Principle and Step-by-Step Procedure of Abdominal Hysterectomy: Part 2
}

\author{
Ikuo Konishi, MD, $\mathrm{PhD}^{1}$ \\ ${ }^{1}$ National Hospital Organization, Kyoto Medical Center, Kyoto, Japan \\ Surg J 2019;5(suppl S1):S11-S21.
}

\begin{abstract}
Address for correspondence Ikuo Konishi, MD, PhD, National Hospital Organization, Kyoto Medical Center, Fukakusa Mukaihata-cho, Fushimi-ku, Kyoto 612-8555, Japan (e-mail: konishi@kuhp.kyoto-u.ac.jp).
\end{abstract}

\author{
Abstract \\ Keywords \\ - abdominal \\ hysterectomy \\ - standard procedure \\ - uterine fibroids \\ - MRI
}

Abdominal hysterectomy is the ultimate standard operation among various gynecologic surgeries. However, the actual procedure for a patient varies substantially according to the morphological changes of the uterus and adnexa. Therefore, it is important to assess the deviation from standard and the difficulties in the procedure and to plan the modification of the operation at the preoperative conference. In this chapter, a standard step-by-step procedure for abdominal hysterectomy is described.

\section{Preoperative Evaluation}

Clinical conference before surgery is very important for the patient and the doctors. All of medical staffs, not only gynecologists but also radiologists and pathologists if possible, should gather and discuss the precise diagnosis and the operative procedure. ${ }^{1}$ In case of uterine fibroids, the preoperative assessment is especially important, because the clinical diagnosis is not pathological but just presumable. In fact, $5 \%$ of the cases diagnosed preoperatively as benign are pathologically not usual leiomyoma but tumors of other histology such as cellular leiomyoma, dissecting leiomyoma, intravenous leiomyomatosis, endometrial stromal sarcoma, smooth muscle tumor of uncertain malignant potential, and leiomyosarcoma.

Thus, it is very important to confirm again the current case as benign leiomyoma using magnetic resonance imaging (MRI) findings. ${ }^{2}$ If MRI image shows that the tumor has uniform lowintensity in T2-weighted image and well demarcated, it is absolutely benign leiomyoma ( $\mathbf{- F i g}$. $\mathbf{1}$ ). Low-intensity with several furrow-like high-intensity strings also indicates benign (- Fig. 2). In MRI, however, T2-weighted image with heterogeneous high-intensity and fine granular shadow represents higher cellularity of tumor cells. High-intensity in T1-weighted image suggests the presence of intratumoral bleeding. Defect in contrast-enhanced image indicates the necrosis in the tumor. These MRI findings strongly suggest that this tumor is not usual leiomyoma but may be leiomyosarcoma ( - Fig. 3). When considering the possibility of sarcoma, the attitude of surgeon must change at hysterectomy. Especially, in case planning myomectomy or planning laparoscopic surgery, it is much more serious for both careful explanation to the patient and careful surgery with "non-touch" technique for the tumor.

In addition, the direction of myoma growing is extremely various, such as submucosal, subserosal, pedunculated, and retroperitoneal. This variation strongly influences the operative procedure. In case of huge cervical myoma, the risk of ureteral injury increases significantly. Therefore, preoperative planning of the surgery along with looking at MRI findings is essential for the safe and reliable operation for the patient.
Surgical Steps
1. Opening Abdomen and Exploration
$\downarrow$
2. Round Ligament and Peritoneum
$\downarrow$
3. Infundibulopelvic Ligament and Adnexa
$\downarrow$
4. Mobilization of Bladder
$\downarrow$
5. Cardinal Ligament
$\downarrow$
6. Amputation and Closure of Vagina
$\downarrow$
7. Closing Abdomen

DOI https://doi.org/ 10.1055/s-0038-1676467. ISSN 2378-5128.
Copyright (c) 2019 by Thieme Medical Publishers, Inc., 333 Seventh Avenue, New York, NY 10001, USA. Tel: +1(212) 584-4662.
License terms (c) (1) $\ominus$ (\$) 

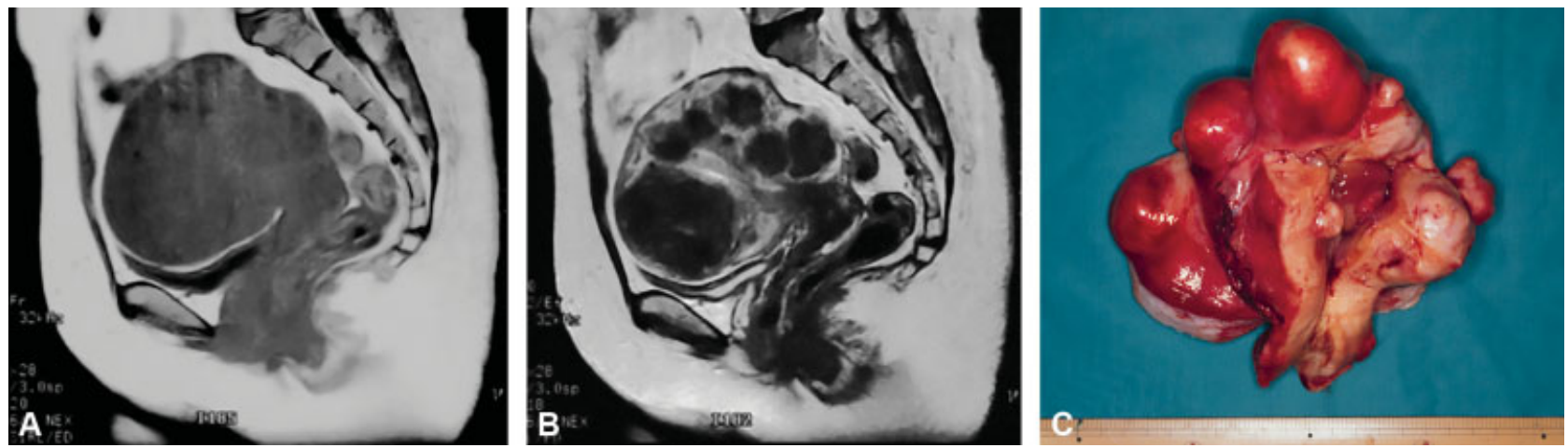

Fig. 1 Magnetic resonance imaging (MRI) findings of typical benign leiomyomas. If MRI image shows that the tumor has uniform low-intensity in T2-weighted image and well demarcated, it is absolutely benign leiomyoma. (A) T1-weighted image. (B) T2-weighted image. (C) Hysterectomy specimen of multiple benign leiomyomas.
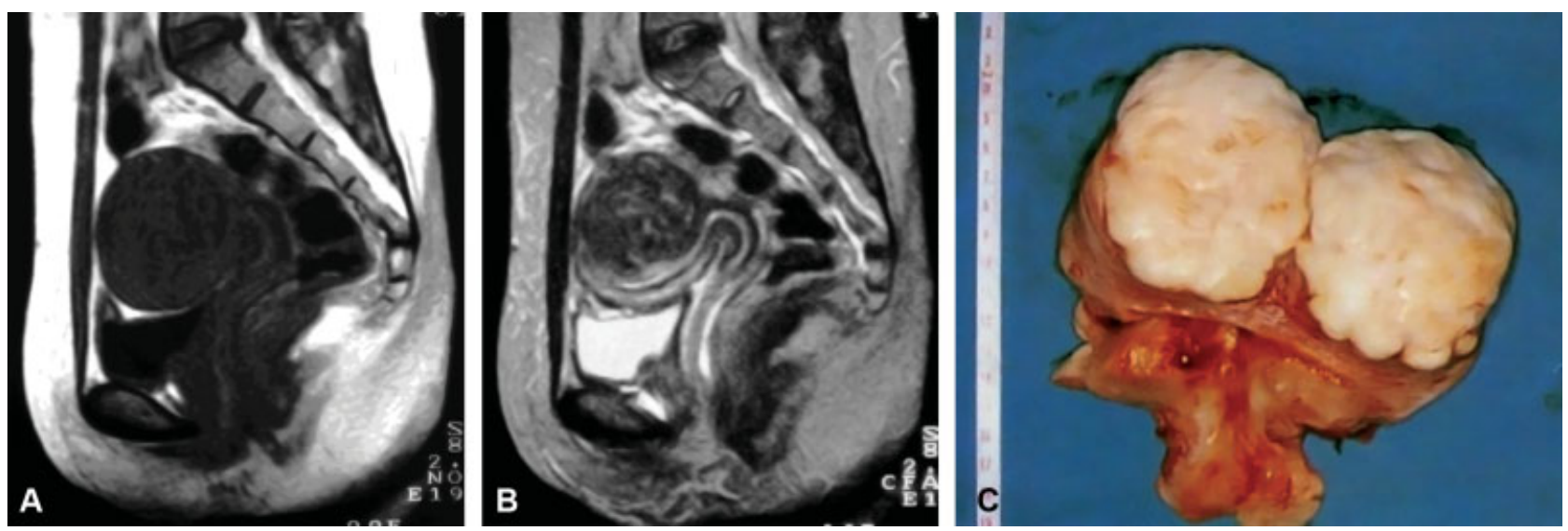

Fig. 2 Magnetic resonance imaging findings of usual benign leiomyoma. Low-intensity in T2 with several furrow-like high-intensity strings also indicates benign leiomyoma. (A) T1-weighted image. (B) T2-weighted image. (C) Cut section of typical benign leiomyoma.
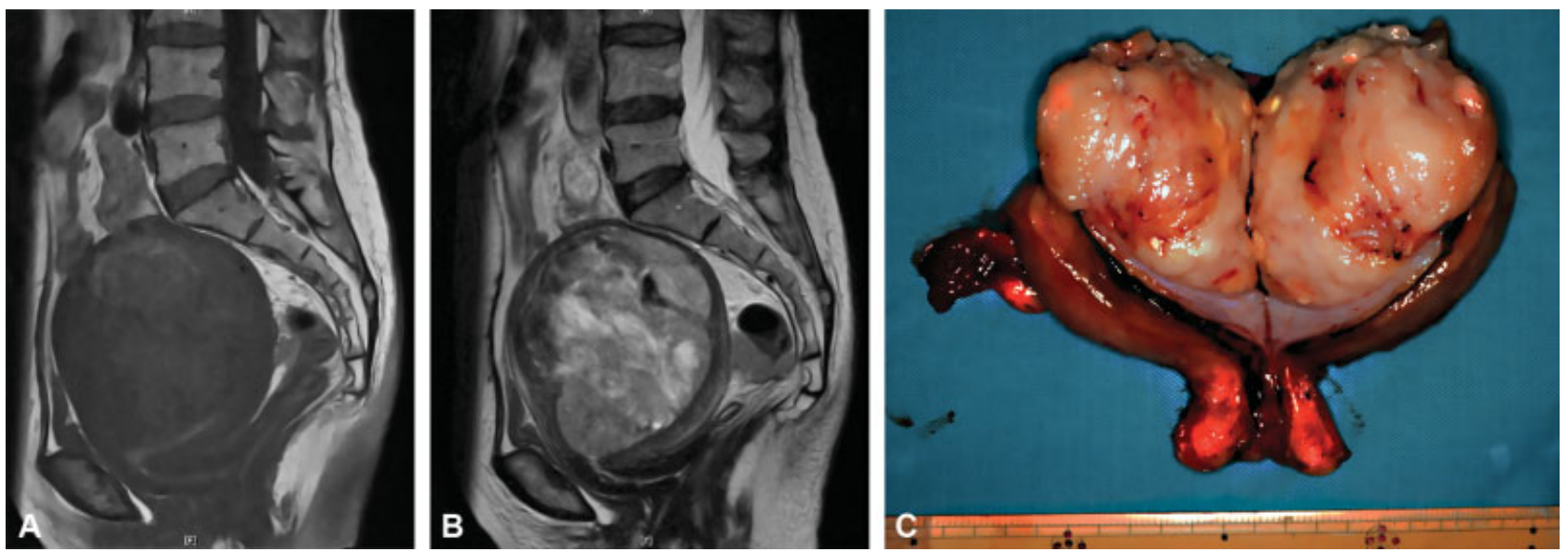

Fig. 3 Magnetic resonance imaging (MRI) findings of leiomyosarcoma. T2-weighted image with heterogeneous high-intensity and fine granular shadow represents higher cellularity of tumor cells. High-intensity in T1-weighted image suggests the presence of intratumoral bleeding. These MRI findings strongly suggest that this tumor is not usual leiomyoma but leiomyosarcoma. (A) T1-weighted image. (B) T2-weighted image.

(C) Cut section of typical leiomyosarcoma.

\section{Explanation of Procedures}

Abdominal hysterectomy has been indicated frequently for uterine fibroids. Due to great variation in size and shape of the uterus due to the various development of leiomyo- mata, the surgical procedure often deviates from the standard. However, gynecologic surgeon should have some standard plan, and then modify it according to the anatomical variation. Here, a standard operation technique is presented. 


\section{Opening Abdomen and Exploration}

Patient is laid in the supine position and urethral catheter is inserted for continuous bladder drainage. Keeping the bladder empty is very important for safe operation. Trendelenburg position is not adopted in the standard. The vaginal cavity is prepared by povidone-iodine before starting surgery.

Usually, the primary operator stands on the left side of patient. The assistant or supervisor stands on the right side and in front of the operator, and plays an important role both in appropriate traction of the uterus and in showing clearly the operative field.

The operator incises the abdominal wall longitudinally from the pubis toward the umbilicus, then the fascia, and the peritoneum. The midline and longitudinal incision is the golden standard for pelvic surgery to facilitate the surgical procedure and to avoid injury to vital structures, even in the modern era of laparoscopic surgery. Only if the uterus is not so large, transverse incision is preferred.

The intestines are softly put upward and maintained with large gauze/sponge, and an appropriate operative field is obtained by the self-retaining retractor.

Before starting surgery, the operator should examine the uterus, adnexae, and the surrounding organs, and check whether unexpected abnormalities and/or adhesions exist or not. If present, restoration of pelvic anatomy by release of adhesions is mandatory for safer operation, except in the surgery for malignancy where the cancer cells exist within the adhesion. If needed, the ascetic fluid is presented to pathology laboratory for cytological examination.

Throughout the surgical procedure, the uterus is always maintained in the appropriate traction by the assistant. Usually so that, a pair of long and straight Kocher clamps are placed between the uterus and the adnexa. The tip of clamp should be at the avascular and transparent space of anterior and posterior of broad ligaments, and should not reach to the uterine vessels below. In the figures of this chapter, however, the clamp was not used and the uterus was treated directly by the hand of assistant.

\section{Round Ligament and Peritoneum}

Since gynecologic surgery is essentially the operation in the retroperitoneum, it is necessary for the operator to enter and explore the retroperitoneal cavity. To do so, the operator must identify the entrance most easy to access, that is, the round ligament. Even in case with distorted anatomy, round ligament can be identified easily. Therefore, hysterectomy usually begins with the round ligament.

The operator grasps and lifts the right-sided round ligament using the forceps, finds the transparent area beneath the ligament, and inserts twice the needle with No. 1-0 absorbable sutures. Then, tie and cut between the ligations with the Cooper scissors. When cutting the ligaments or vessels, it is usually important to put the scissors vertically to the ligament (- Fig. 4) After the cut, air will enter into the retroperitoneal cavity, the loose connective tissues fall down, and the cavity can be seen.

\section{Tips and Warnings}

There are two kinds of surgical procedure for the treatment of ligament. The standard is the clamp/cut first and then ligate, and another is suture/ligation first and then cut. For treatment of the round and infundibulopelvic ligaments, the latter method is usually employed due to its simplicity. In this case, however, the operator should note that the suture tends to be loosen so that double ligation is needed.
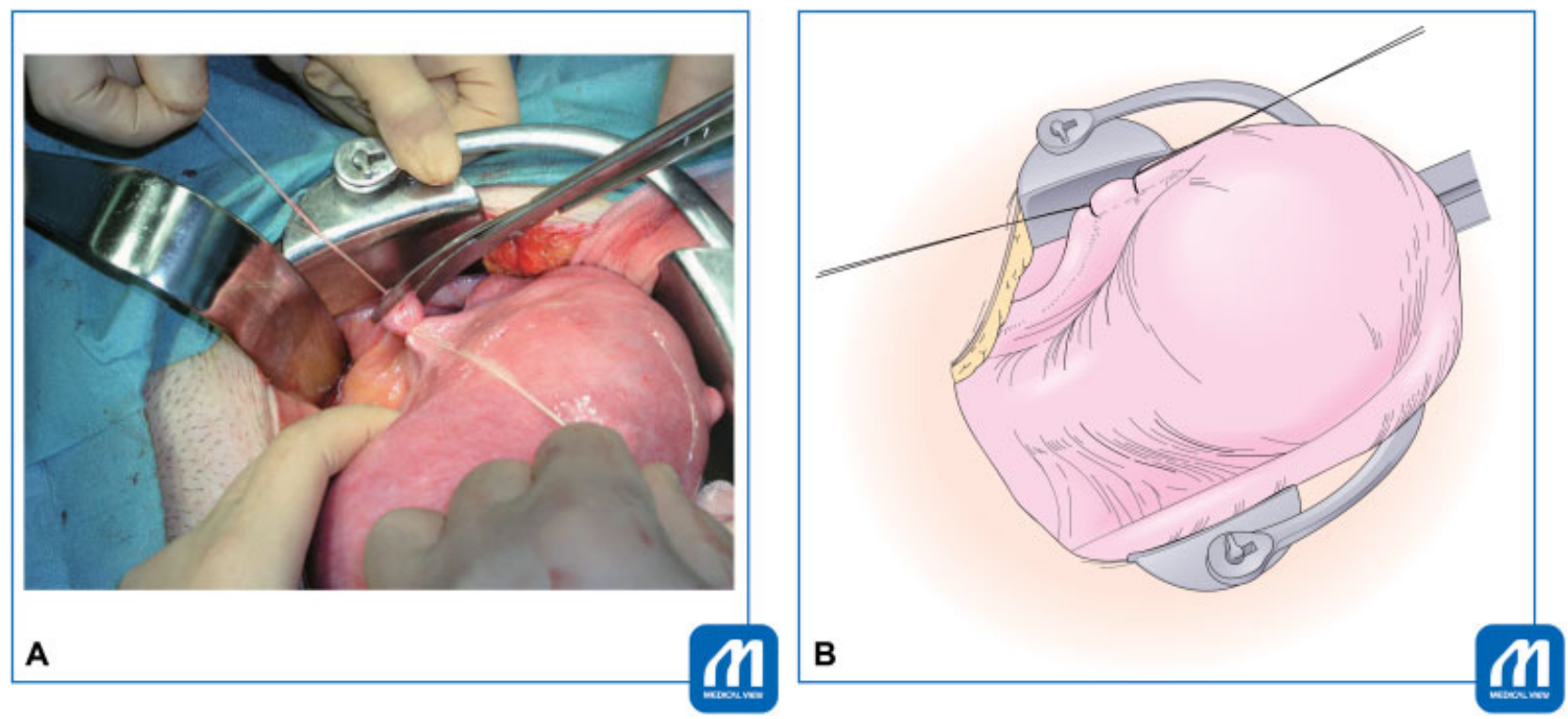

Fig. 4 Ligation and cut of round ligament. (Reproduced with permission from Konishi I. Basic procedure 2. In: Hiramatsu Y, Konishi I, Sakuragi N, Takeda S, eds. Mastering the Essential Surgical Procedures OGS NOW, No.2 Total Abdominal Hysterectomy (Japanese). Tokyo: Medical View; 2010:56-73. Copyright @ Medical View). 
Then, the operator incises the anterior leaf of broad ligament. Before incision, it is important to identify the target endpoint for the incision, because erroneous and deep dissection toward bladder induces bleeding. To identify the point, the operator lifts the broad ligament of vesicouterine pouch, and identify the transitional and freely movable area between the uterine and bladder serosa. Usually the target is $1 \mathrm{~cm}$ downward from the lower end of uterine serosa (-Fig. 5). The incision line is concave-shaped from the round ligament to vesicouterine fossa. Concave-shape is important to avoid unnecessary blood loss from the uterine vessels. Before incision, the broad ligament is lifted with the forceps, and all of the subperitoneal connective tissues are detached with Cooper scissors. This is very important to minimize the bleeding. Then, the thin and transparent peritoneum is incised until the target.
Next step is the incision of middle leaf of broad ligament toward upward. The same dissection of loose connective tissues and incision toward the infundibulopelvic ligament is performed.

\section{Tips and Warnings}

For a right-handed gynecologic surgeon, grasp ability of the left hand is essential for handling forceps and treatment of ligaments. Therefore, it is important for young students and residents to strengthen the grasping power of the left hand in the daily practice and exercise.
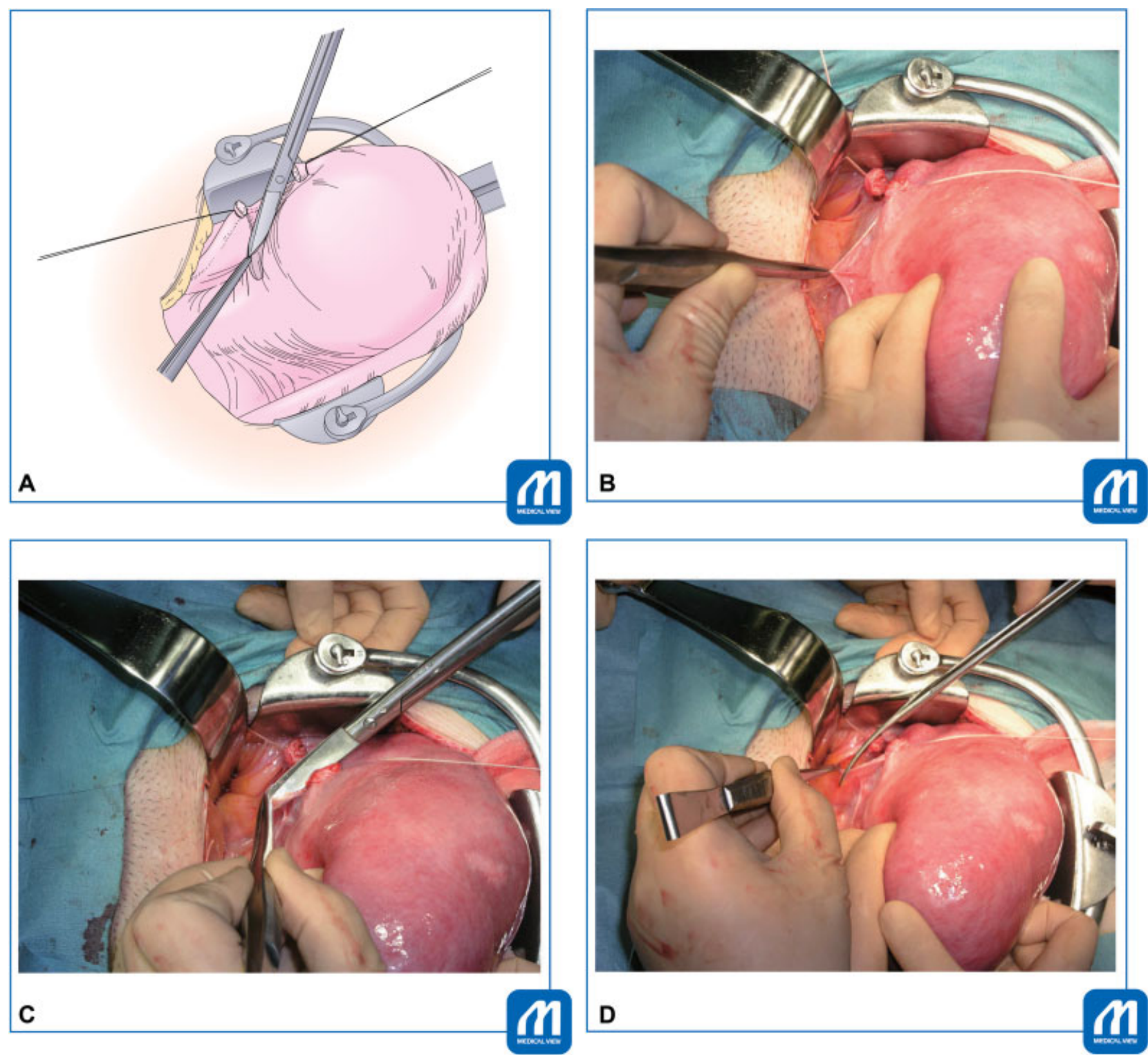

Fig. 5 Incision of anterior leaf of broad ligament. (Reproduced with permission from Konishi I. Basic procedure 2. In: Hiramatsu Y, Konishi I, Sakuragi N, Takeda S, eds. Mastering the Essential Surgical Procedures OGS NOW, No.2 Total Abdominal Hysterectomy (Japanese). Tokyo: Medical View; 2010:56-73. Copyright @ Medical View). 


\section{Tips and Warnings}

For peritoneal incision, the operator should tract the peritoneum intensively and then attach the scissors almost vertically to the peritoneum, push slightly, and scrape down all of the connective tissues beneath the peritoneum. Only a thin and transparent peritoneum remains and can be incised without bleeding ( $\mathrm{O}$ [good]). If the connective tissues are incompletely detached, the veins and capillaries remain in the peritoneal side, and so the incision results in bleeding (X [bad]). Such procedure is also important in case of detachment of ureter, bladder, and rectum from the neighboring tissues (-Fig. 6 ).

\section{Tips and Warnings}

For identification of the right ureter, the operator should use the left hand, first insert the index finger in the retroperitoneal side, and attach the thumb to the peritoneal side of the posterior leaf of broad ligament. When touch the ureter by these fingers, the operator feels the "snapping" sensation, being characteristic to ureter ( $\boldsymbol{- \text { Fig. }}$ 7). The operator should palpate the posterior leaf of broad ligament using his fingers, and confirm the ureter running 2 to $4 \mathrm{~cm}$ apart from the ovarian artery and vein. Then, insert the suture needle apart from the ureter ( - Fig. 8 ).

\section{Infundibulopelvic Ligament and Adnexa}

If the hysterectomy will be done along with salpingo-oophorectomy, the infundibulopelvic ligament shall be cut. Here is the

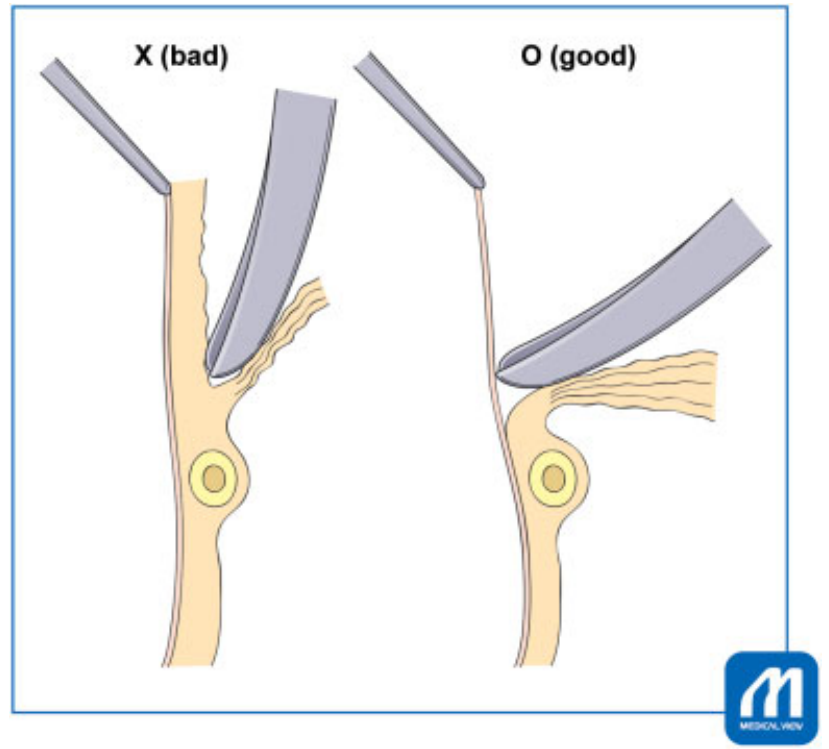

Fig. 6 Incision of peritoneum. (Reproduced with permission from Konishi I. Basic procedure 2. In: Hiramatsu Y, Konishi I, Sakuragi N, Takeda S, eds. Mastering the Essential Surgical Procedures OGS NOW, No.2 Total Abdominal Hysterectomy (Japanese). Tokyo: Medical View; 2010:56-73. Copyright @ Medical View).

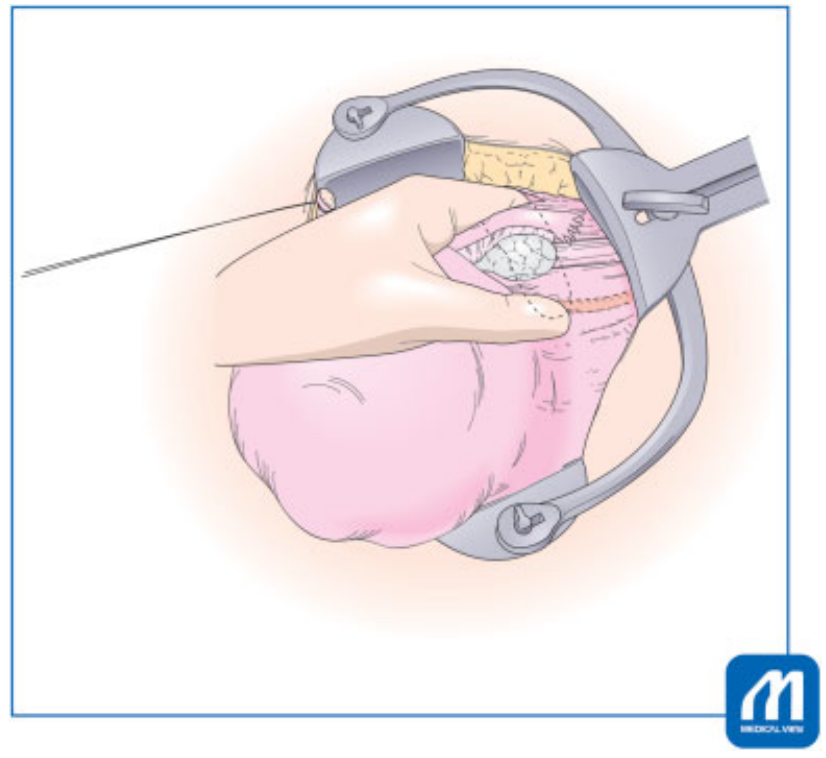

Fig. 7 Identification of the right ureter. (Reproduced with permission from Konishi I. Basic procedure 2. In: Hiramatsu Y, Konishi I, Sakuragi $\mathrm{N}$, Takeda S, eds. Mastering the Essential Surgical Procedures OGS NOW, No.2 Total Abdominal Hysterectomy (Japanese). Tokyo: Medical View; 2010:56-73. Copyright $\odot$ Medical View).

first important point to identify the running of ureter to prevent the ureteral injury. The operator should palpate the posterior leaf of broad ligament using his fingers, and confirm the ureter running 2 to $4 \mathrm{~cm}$ apart from the ovarian artery and vein. The ligament is ligated using $1-0$ absorbable sutures, and is cut with Cooper scissors. Then, the upper stump of the ligament should be again ligated for safety. To prevent postoperative bleeding, double ligation of the infundibulopelvic ligament is always necessary in all gynecologic surgeries.

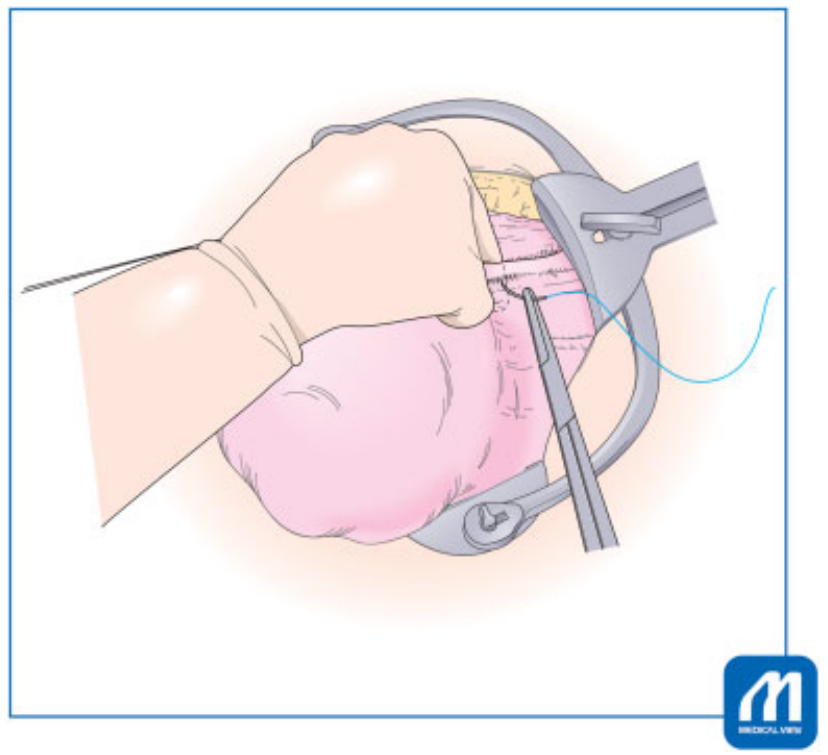

Fig. 8 Ligation and cut of infundibulopelvic ligament. (Reproduced with permission from Konishi I. Basic procedure 2. In: Hiramatsu Y, Konishi I, Sakuragi N, Takeda S, eds. Mastering the Essential Surgical Procedures OGS NOW, No.2 Total Abdominal Hysterectomy (Japanese). Tokyo: Medical View; 2010:56-73. Copyright $\odot$ Medical View). 


\section{Tips and Warnings}

For identification of the right ureter, the operator should use the left hand, first insert the index finger in the retroperitoneal side, and attach the thumb to the peritoneal side of the posterior leaf of broad ligament. When touch the ureter by these fingers, the operator feels the "snapping" sensation, being characteristic to ureter. Thus, the operator can identify the ureter running, and confirm the insertion point of the suture needle is apart from the ureter.

If the adnexal organs are to be conserved, both the ovarian ligament and the tube are clamped with the two forceps, cut, and then ligated with the 8-figure sutures. Double ligation is also needed here, since the first suture tends to slide off from the stump of ligament. Recently, only salpingectomy is frequently performed considering the possible tubal origin of ovarian cancer. In this case, mesosalpinx is clamped several times, cut, and ligated.

Then, the posterior part of broad ligament is incised. Here, it is also important to determine the target endpoint of incision, that is the uterine origin of sacrouterine ligament. The operator should tract the peritoneum intensively and then attach the scissors almost vertically to the peritoneum, push slightly, and scrape down all of the connective tissues beneath the peritoneum. Sometimes, the operator can see here the running of the ureter (-Fig. 9).

\section{Tips and Warnings}

While incising the peritoneum, the operator should tract it intensively and then attach the scissors almost vertically to the peritoneum, push slightly, and scrape down all of the connective tissues beneath the peritoneum. Only a thin and transparent peritoneum remains and can be incised without bleeding. If the connective tissues are incompletely detached, the veins and capillaries remain in the peritoneal side, and so the incision results in bleeding. Such procedure is also important in case of detachment of ureter, bladder, and rectum from the neighboring tissues.
All of the above procedures are done for the left-sided round ligament, broad ligament, and infundibulopelvic ligament or adnexa. Now, all of the peritoneal surface except the cul-de-sac peritoneum are incised, and the uterus is now almost free from the serosa. From now, the surgical procedures in the retroperitoneal space start.

\section{Mobilization of Bladder}

It is important to start the bladder mobilization at the midline of cervix, to prevent bleeding from the lateral-sided vesicouterine ligaments. Before the start of mobilization of bladder, therefore, the operator should palpate the cervix from both anterior and posterior sides of uterus to confirm the position of the cervix. This is because the cervix frequently deviates laterally due to fibroids or adhesion (-Fig. 10). Palpation is also essential to assess the height of lower end of cervix or vaginal fornix.

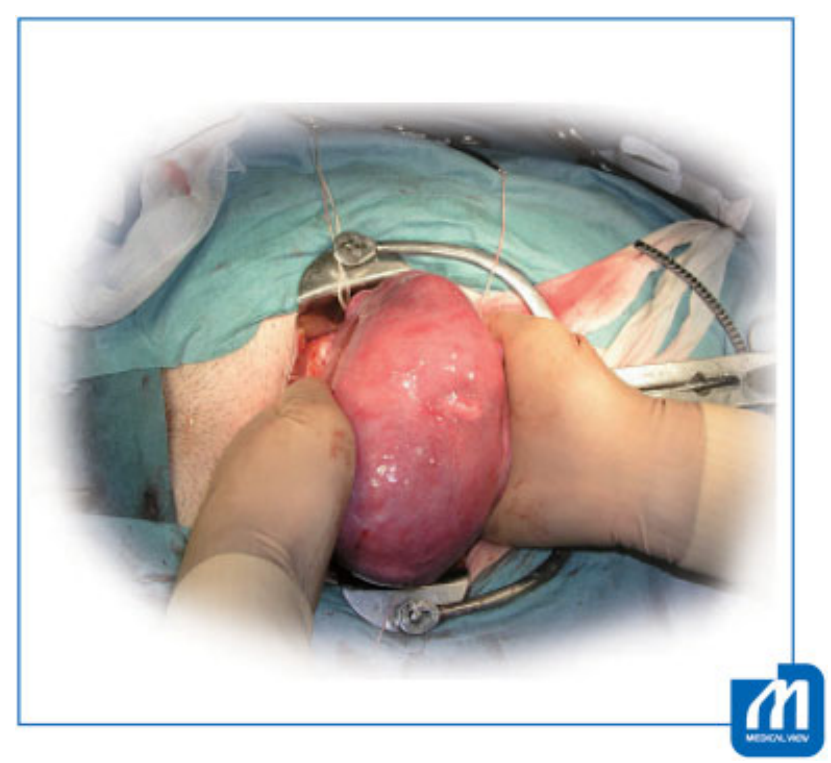

Fig. 10 Palpation of uterine cervix. (Reproduced with permission from Konishi I. Basic procedure 2. In: Hiramatsu Y, Konishi I, Sakuragi $\mathrm{N}$, Takeda S, eds. Mastering the Essential Surgical Procedures OGS NOW, No.2 Total Abdominal Hysterectomy (Japanese). Tokyo: Medical View; 2010:56-73. Copyright @ Medical View).

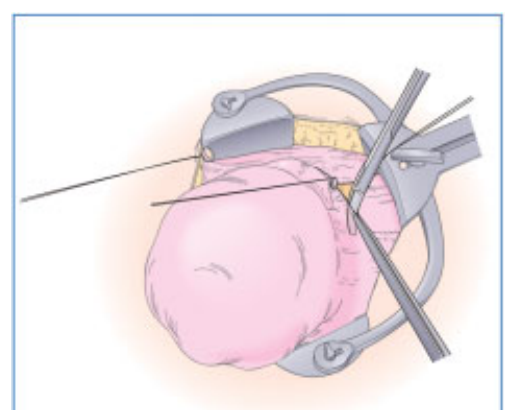

A

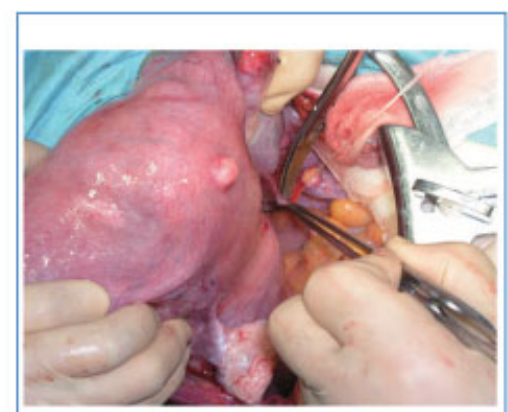

B

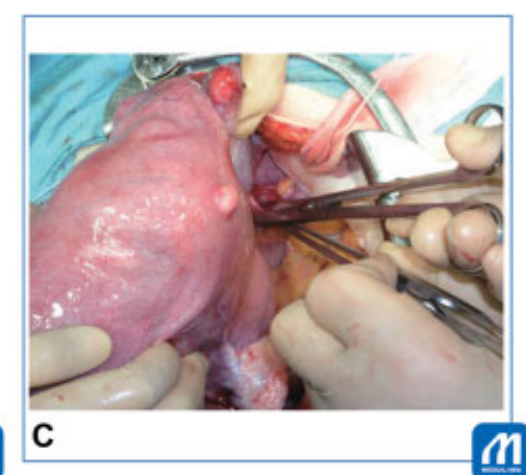

Fig. 9 Incision of posterior leaf of broad ligament. (Reproduced with permission from Konishi I. Basic procedure 2. In: Hiramatsu Y, Konishi I, Sakuragi N, Takeda S, eds. Mastering the Essential Surgical Procedures OGS NOW, No.2 Total Abdominal Hysterectomy (Japanese). Tokyo: Medical View;2010:56-73. Copyright @ Medical View). 
When the operator lifts the cut-end of anterior leaf of broad ligament, the connective tissues in the vesicouterine pouch spontaneously sink, where the first incision should be made in the center of cervix. Pushing the Cooper scissors vertically to cervix and cutting the connective tissues will disclose the surface of cervix, which is white, smooth, and shining. Then, the connective tissues and the bladder are dissected downward using the scissors from the cervix completely until the portion of lower end of cervix ( $\mathbf{- F i g . ~ 1 1 ) . ~ T h e n , ~ t h e ~ o p e r a t o r ~}$ will treat the lateral vesicouterine ligaments. Loose connective tissues on the surface of ligaments are carefully removed. Since it is rich in vasculature, the dissection should not be done deeply to avoid bleeding. The bladder is now mobilized to the appropriate level of height, $\sim 1 \mathrm{~cm}$ below the vaginal fornix.

The L-shaped retractor is placed at the detached portion, pushing the bladder downward (-Fig. 12).

Usually, mobilization of rectum from the uterus is not necessary, because the operator can directly approach the posterior wall of vagina through the cul-de-sac peritoneum. In the case complicated with endometriosis, however, the cul-de-sac is closed and the rectum is adhered to the vagina and cervix. In such case, the dissection of the rectum from the cervix is needed. Before this procedure, the operator should identify the sacrouterine ligament for anatomical understanding, and the ligaments are cut and ligated before hysterectomy. Cutting the sacrouterine ligament will always facilitate the movability of uterus for easier hysterectomy.

\section{Cardinal Ligament}

Now, it is the time for clamping and cutting the uterine vessels of cardinal ligament. Before that, it is necessary to carefully dissect and removethelooseconnectivetissueon theuterinearteryand vein. Removal of the connective tissues on the vesicouterine ligament is also important for prevention of ureteral injury. Thus, theascending branch of the uterinearteryandveinswill be skeletonized ( - Fig. 13). To avoid the ureteral injury, it is very important, by the assistant, to keep the uterus in the traction upward and to push the bladder downward using L-shaped retractor. And then, the operator should palpate the ureter running along the posterior leaf of broad ligament, to identify

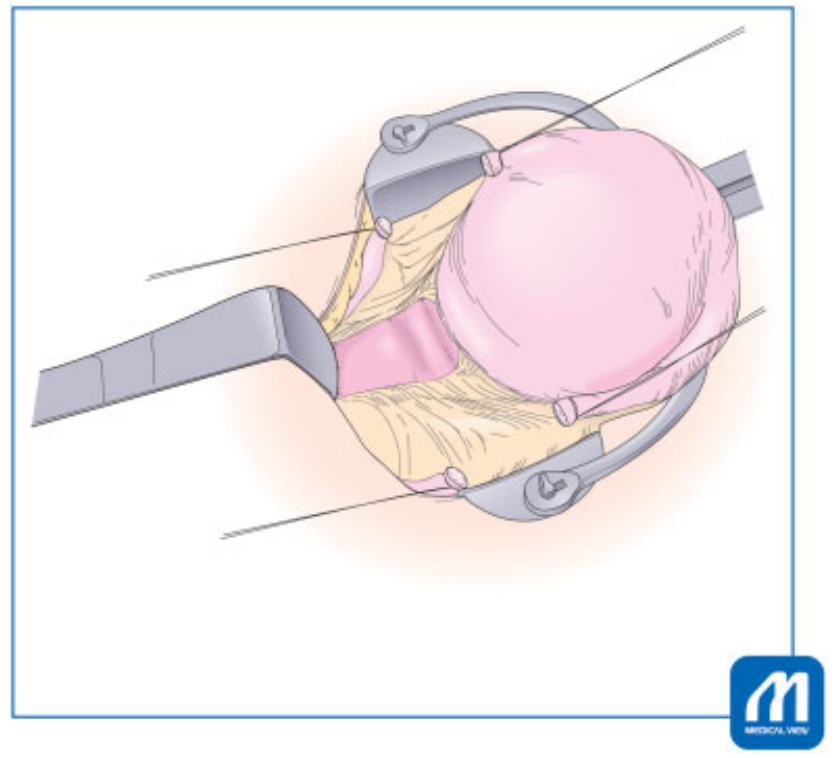

Fig. 12 Application of L-shaped retractor. (Reproduced with permission from Konishi I. Basic procedure 2. In: Hiramatsu Y, Konishi I, Sakuragi N, Takeda S, eds. Mastering the Essential Surgical Procedures OGS NOW, No.2 Total Abdominal Hysterectomy (Japanese). Tokyo: Medical View; 2010:56-73. Copyright (c) Medical View).

the level of ureterentering the cardinal ligament 1 to $3 \mathrm{~cm}$ lateral from the cervix and 2 to $4 \mathrm{~cm}$ below the uterine artery.

In general, the cardinal ligament including uterine artery and veins will be cut two times until reaching the vaginal fornix (twosteps clamping for cardinal ligament). The first clamp is placed at an angle of $45^{\circ}$ for the upper half of the cervix, so that the tip of clamp reaching $1 \mathrm{~cm}$ below the height of internal os of the uterus. At clamping, it is desirable to have the clamp slide off the surface of the cervix, to all of vessels be completely clamped (-Fig. 14). When the first clamp is placed, the operator is asked to palpate again the ureter, and will confirm the distance between the tip of clamp and the ureter, that is usually 2 to $3 \mathrm{~cm}$ apart. Another upper clamp is then placed to prevent backflow bleeding from the uterus. Then, the upper half of ligament is cut with Cooper scissors, needled, and ligated with 1-0 absorbable suture. The cut-end of uterine artery needs double ligation ( - Fig. 15).
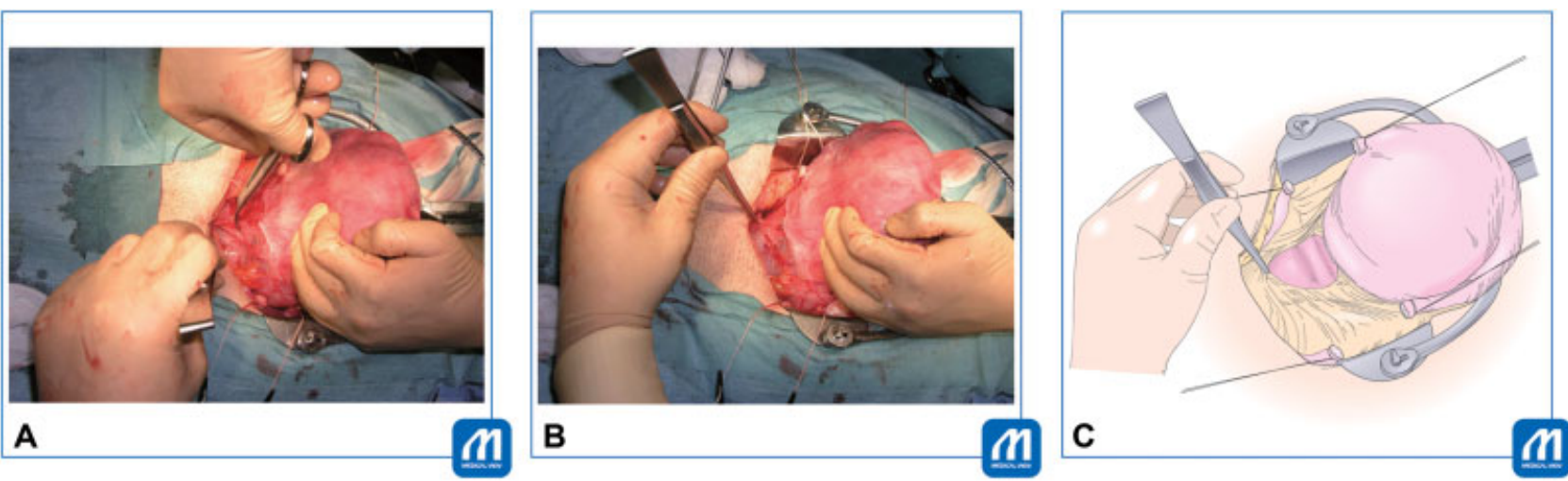

Fig. 11 Mobilization of bladder. To prevent bleeding from the lateral vesicouterine ligaments, it is important to start the dissection at the midline of cervix. When lifting the anterior leaf of broad ligament in the center, the connective tissues in the vesicouterine pouch sink. Pushing the Cooper scissors vertically to cervix and cutting the sinking tissues will disclose the surface of cervix. Then, the connective tissues and the bladder are dissected downward using the scissors. (Reproduced with permission from Konishi I. Basic procedure 2. In: Hiramatsu Y, Konishi I, Sakuragi N, Takeda S, eds. Mastering the Essential Surgical Procedures OGS NOW, No.2 Total Abdominal Hysterectomy (Japanese). Tokyo: Medical View; 2010:56-73. Copyright @ Medical View). 


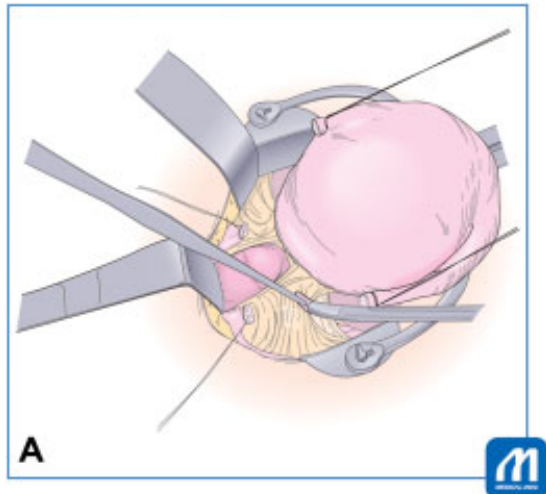

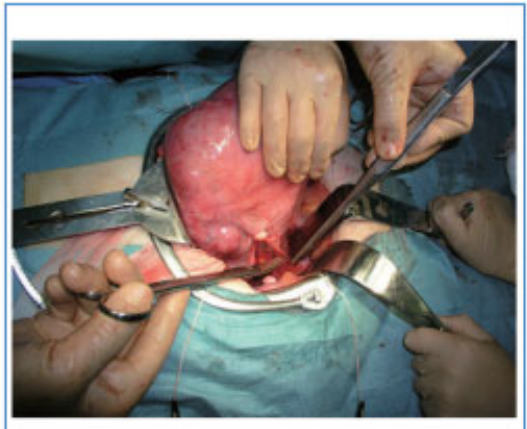

B

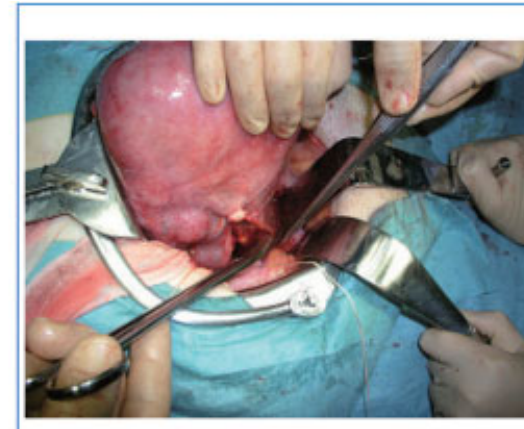

C

Fig. 13 Dissection of connective tissues on cardinal ligament. (Reproduced with permission from Konishi I. Basic procedure 2. In: Hiramatsu Y, Konishi I, Sakuragi N, Takeda S, eds. Mastering the Essential Surgical Procedures OGS NOW, No.2 Total Abdominal Hysterectomy (Japanese). Tokyo: Medical View; 2010:56-73. Copyright @ Medical View).

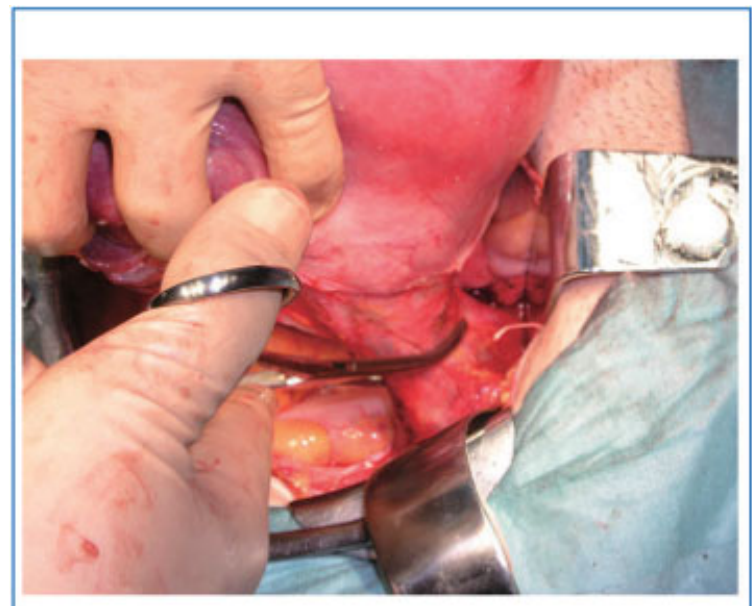

A

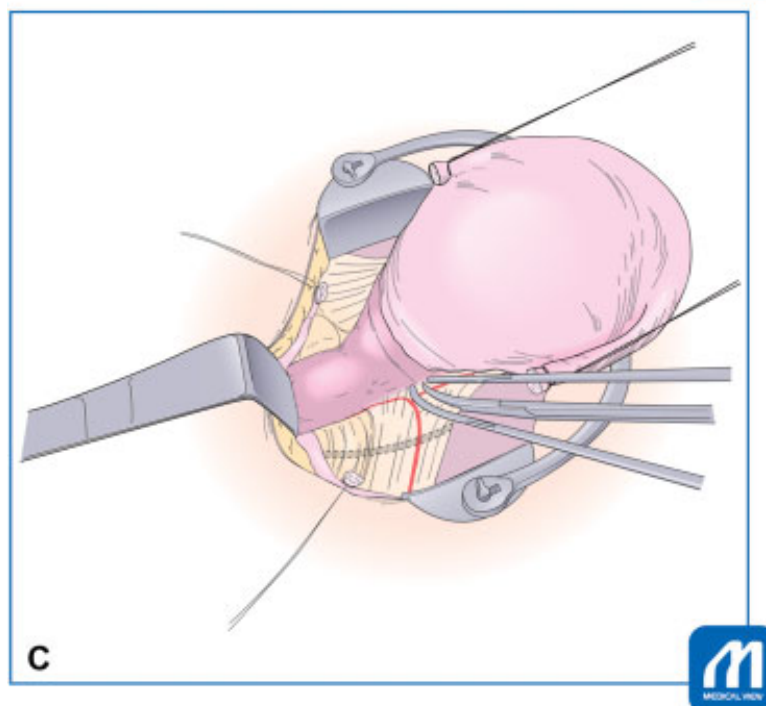

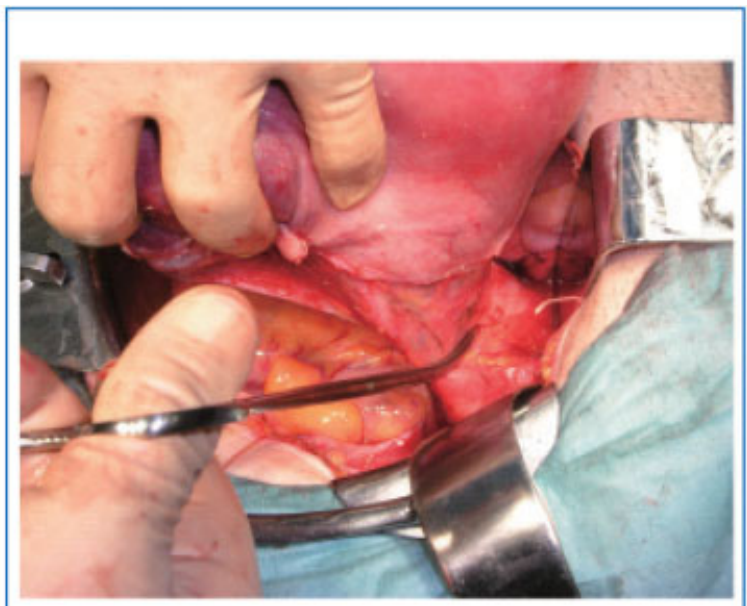

B
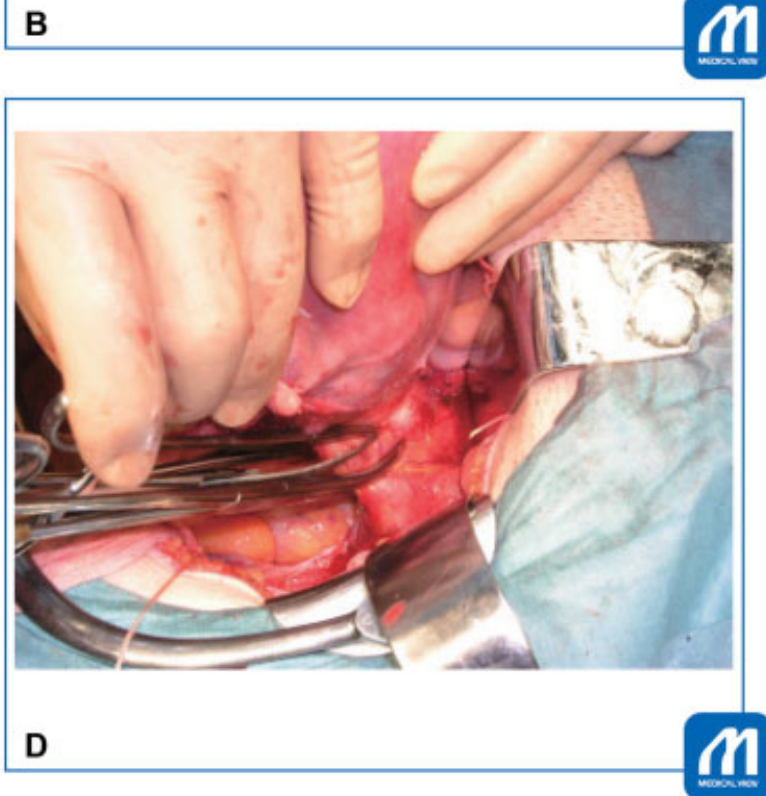

Fig. 14 Cut and ligation of cardinal ligament. Cardinal ligament including uterine artery and veins is cut two times until reaching the vaginal fornix (two-step clamping). First, the operator should palpate the ureter running. Then, the first clamp is placed at an angle of $45^{\circ}$ for the upper half of the cervix, so that the tip of clamp reaches $1 \mathrm{~cm}$ below the height of internal os of uterus. At clamping, it is desirable to have the clamp slide off the surface of the cervix, to all of vessels be completely clamped. Another upper clamp is placed to prevent backflow bleeding from the uterus. The operator is asked to palpate again the ureter, and confirm the distance between the tip of clamp and the ureter, that is usually 2 to $3 \mathrm{~cm}$ apart. Then, the upper half of ligament is cut with Cooper scissors. (Reproduced with permission from Konishi I. Basic procedure 2. In: Hiramatsu Y, Konishi I, Sakuragi N, Takeda S, eds. Mastering the Essential Surgical Procedures OGS NOW, No.2 Total Abdominal Hysterectomy (Japanese). Tokyo: Medical View; 2010:56-73. Copyright @ Medical View). 
Then the second clamp is placed along the cervix for hemostasis from small veins from the ligament. The tip of clamp reaches the level of the vaginal fornix, and then the lower half of cardinal ligament is cut and sutured (-Fig. 16). During cutting the cardinal ligament here, the operator can recognize the plane demarcating the cervix from the ligament. When entered this true plane, especially near the sacrouterine ligament, the operator feels very easy and smooth for the cutting. The cutting has finally reached the level of vaginal fornix. It is important to avoid too deep cutting into the paracolpium, which results in the substantial amount of bleeding.

After the same procedure is done for the left side, it is the time to proceed the final step for hysterectomy. Usually, it is not necessary to cut the sacrouterine ligament, which will be cut simultaneously during the amputation of vagina.

\section{Tips and Warnings}

To avoid injury of the ureter during the ligation of cardinal ligament, such "two-steps clamping" is essential. Each step eventually moves the ureter laterally apart from the cervix and vagina, and so this is safer compared with onestep clamping. In case of longer cervix, three-steps clamping shall be considered.

However, too many steps of clamp and ligation for cardinal ligament tend to produce the bleeding between many cut-ends of ligament. Thus, two or three clamps might be ideal for the treatment of cardinal ligament.

The operator can palpate the running ureter anytime during the surgical procedure, and should confirm the distance between the ligation and the ureter.

When severe endometriosis or cervical myoma lifts the ureter running close to the uterus, the operator should denude and isolate the ureter from the posterior leaf of broad ligament, and mark it using yellow-colored tape.

\section{Amputation and Closure of Vagina}

A large gauze is placed in the Douglas pouch, and the transitional area between the cervix and vagina is again palpated. Then, the sharp scalpel will be inserted vertically into the uppermost portion of the anterior wall of vagina (-Fig. 17). The portio and vagina are prepared by povidoneiodine, and a gauze is inserted into the vaginal cavity. The long straight Kocher clamps are sequentially placed on the cut-end of vaginal wall for hemostasis (-Fig. 18). The sacrouterine ligament is simultaneously cut and clamped together with vaginal wall. If the curved Kelly clamp is placed along the vaginal fornix as landmark, it is easier to cut the vagina with the scalpel or scissors along the curve of clamp. The vaginal vault is closed with Z-figure sutures (-Figs. 19 and 20).

\section{Tips and Warnings}

The most frequent point with ureteral injury is during hemostasis against the bleeding from surrounding the vaginal vault. Condition of traction for uterus has gone after hysterectomy, and without traction, the vaginal vault has come very close to the ureter running. Thus, hemostatic sutures without traction of the vaginal vault, near the cut-ends of cardinal ligament, tend to involve the ureteral injury. Therefore, to prevent the injury, the operator should restore the condition of traction; tract again the vaginal vault upward and push the bladder downward. This procedure will move the ureter laterally again. Then, the operator should identify the small point of bleeding and place the superficial hemostatic suture. The operator should not suture deeply into the ligament.
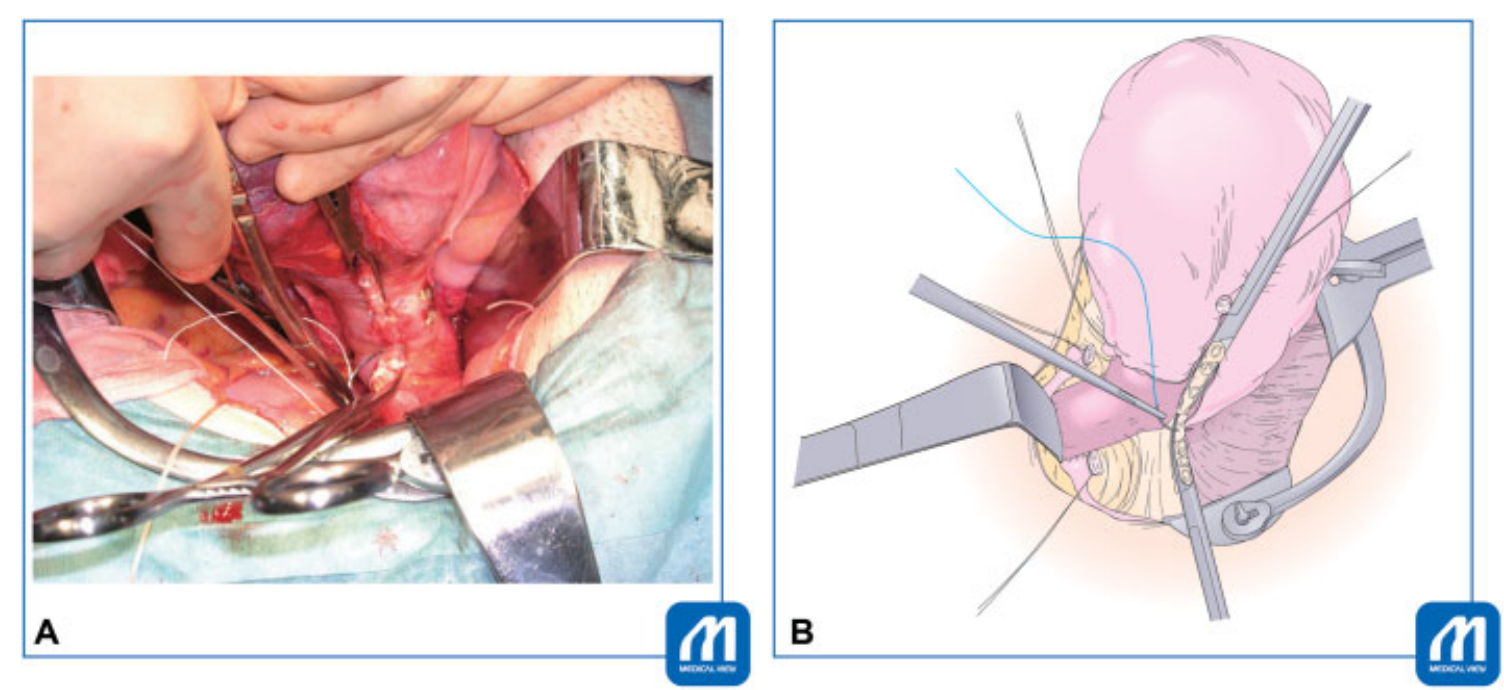

Fig. 15 Cut and ligation of the first clamp for cardinal ligament. (Reproduced with permission from Konishi I. Basic procedure 2. In: Hiramatsu Y, Konishi I, Sakuragi N, Takeda S, eds. Mastering the Essential Surgical Procedures OGS NOW, No.2 Total Abdominal Hysterectomy (Japanese). Tokyo: Medical View; 2010:56-73. Copyright @ Medical View). 


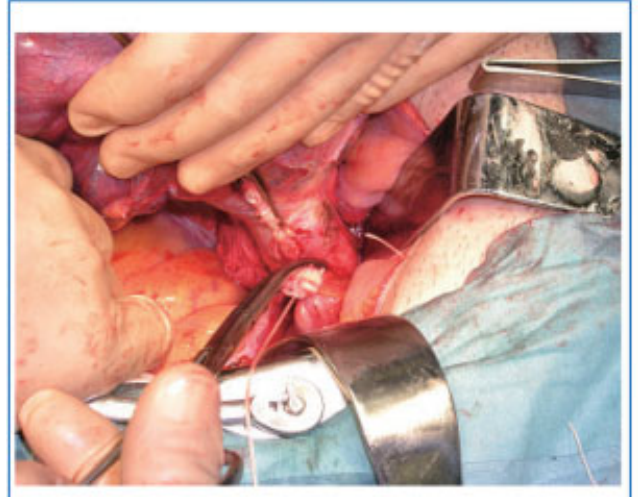

A
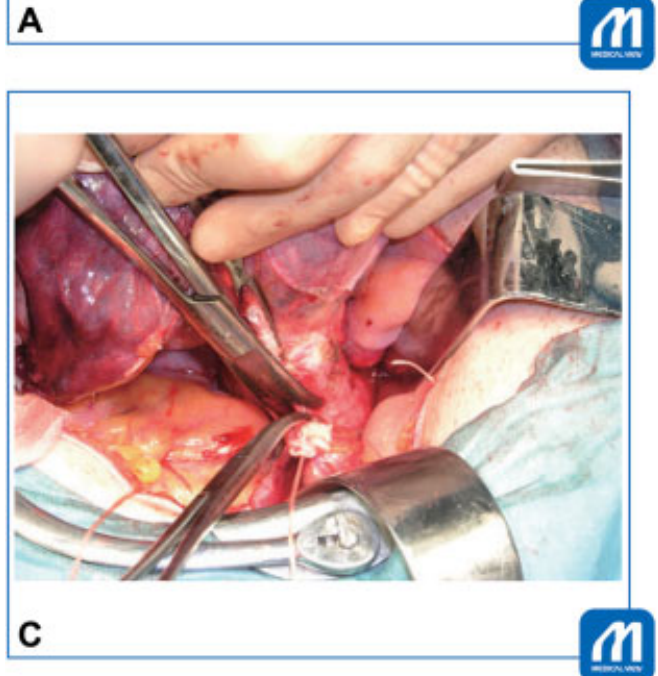
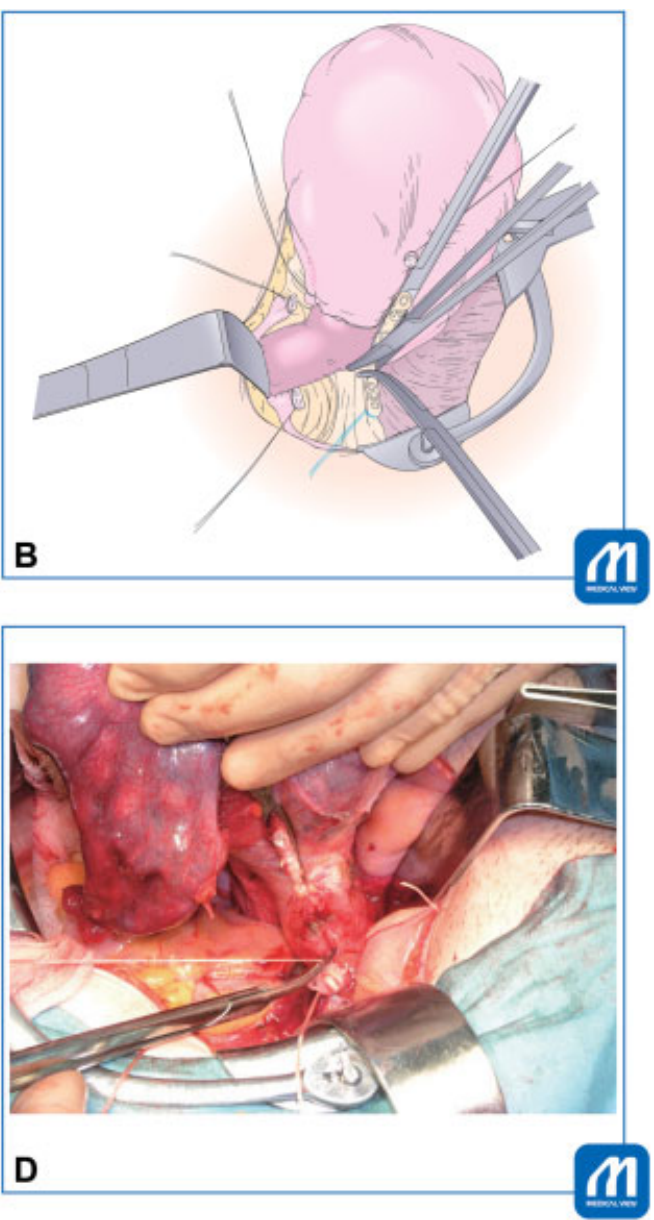

Fig. 16 Cut and ligation of the second clamp for cardinal ligament. (Reproduced with permission from Konishi I. Basic procedure 2. In: Hiramatsu Y, Konishi I, Sakuragi N, Takeda S, eds. Mastering the Essential Surgical Procedures OGS NOW, No.2 Total Abdominal Hysterectomy (Japanese). Tokyo: Medical View; 2010:56-73. Copyright @ Medical View).

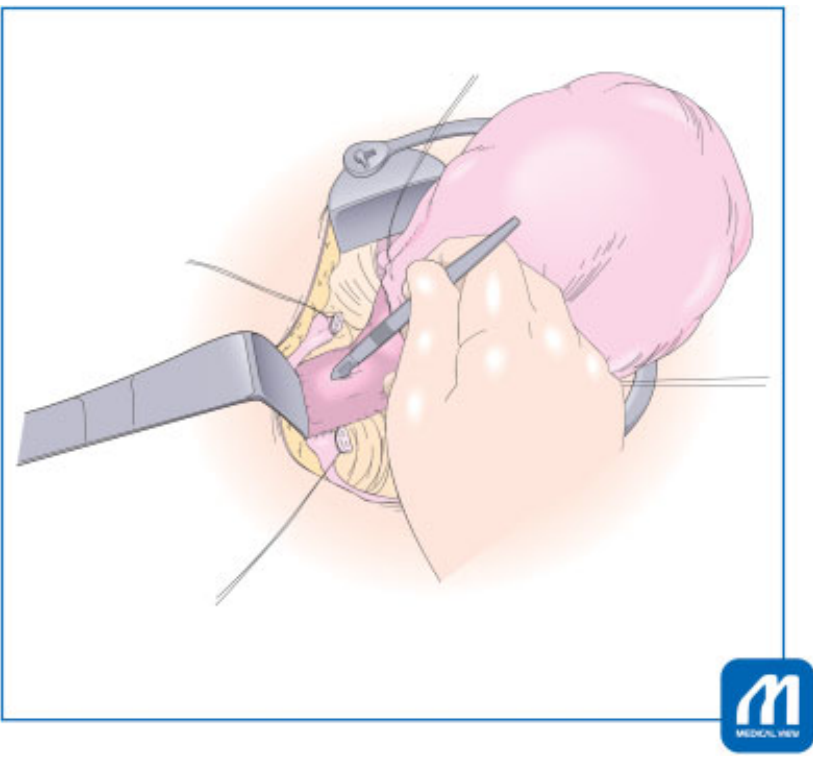

Fig. 17 Incision of vaginal wall. (Reproduced with permission from Konishi I. Basic procedure 2. In: Hiramatsu Y, Konishi I, Sakuragi N, Takeda S, eds. Mastering the Essential Surgical Procedures OGS NOW, No.2 Total Abdominal Hysterectomy (Japanese). Tokyo: Medical View; 2010:56-73. Copyright @ Medical View).

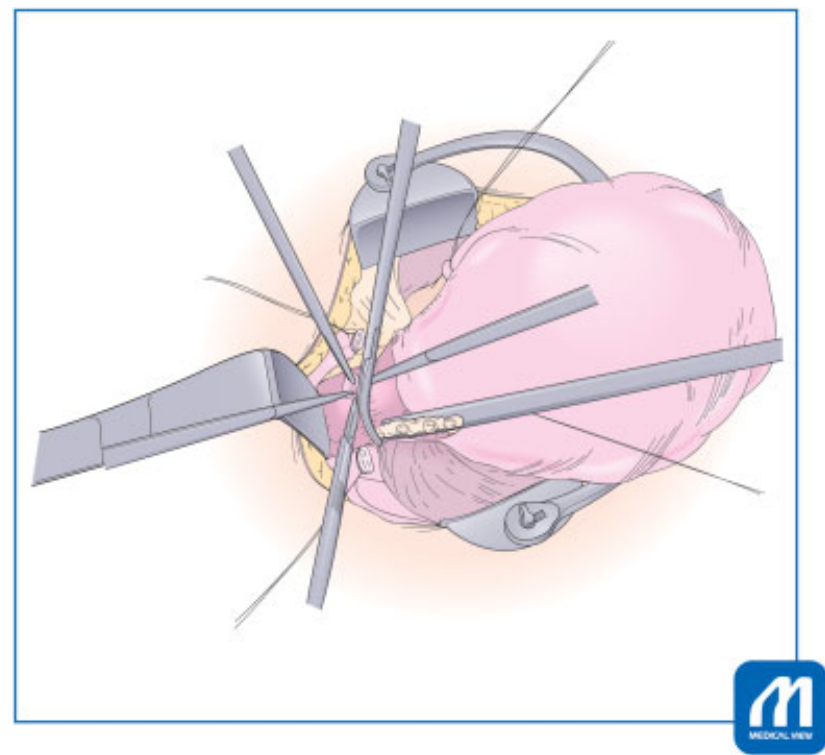

Fig. 18 Placing clamp along vaginal fornix. (Reproduced with permission from Konishi I. Basic procedure 2. In: Hiramatsu Y, Konishi I, Sakuragi N, Takeda S, eds. Mastering the Essential Surgical Procedures OCS NOW, No.2 Total Abdominal Hysterectomy (Japanese). Tokyo: Medical View; 2010:56-73. Copyright @ Medical View). 


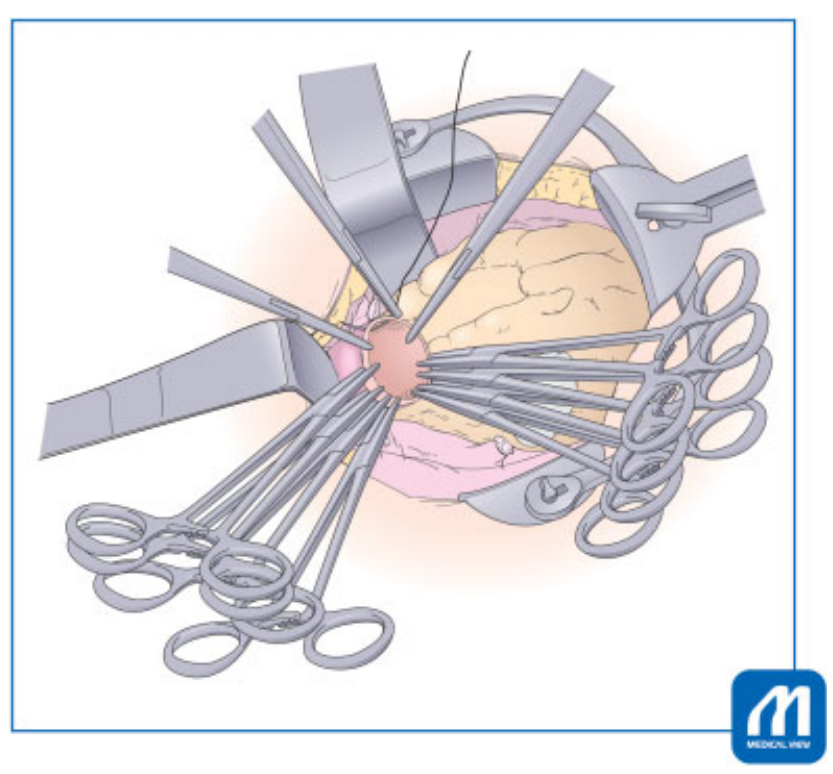

Fig. 19 Suture of vaginal wall. The sacrouterine ligament is simultaneously cut and clamped together with vaginal wall. Careful suture is important at the lateral end of vagina, close to the stump of cardinal ligament. (Reproduced with permission from Konishi I. Basic procedure 2. In: Hiramatsu Y, Konishi I, Sakuragi N, Takeda S, eds. Mastering the Essential Surgical Procedures OGS NOW, No.2 Total Abdominal Hysterectomy (Japanese). Tokyo: Medical View; 2010:56-73. Copyright $@$ Medical View).

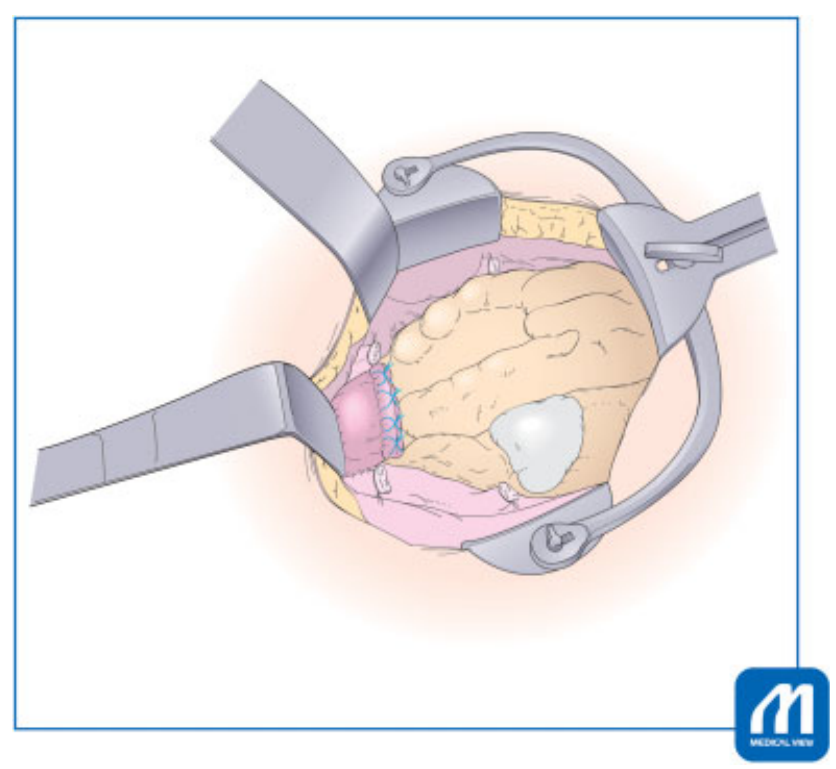

Fig. 20 Closure of vagina. The vaginal vault is closed with Z-figure sutures. (Reproduced with permission from Konishi I. Basic procedure 2. In: Hiramatsu Y, Konishi I, Sakuragi N, Takeda S, eds. Mastering the Essential Surgical Procedures OGS NOW, No.2 Total Abdominal Hysterectomy (Japanese). Tokyo: Medical View; 2010:56-73. Copyright @ Medical View).

\section{Closing Abdomen}

The retroperitoneal space is washed by warm saline, and is confirmed for no bleedings and no foreign bodies. Counting the number of gauze is completed. Pelvic peritoneum is sutured with 2-0 continuous sutures, and completely closed. The cut-ends of ligaments are placed retroperitoneally. Care must be taken not to injure the ureter during the continuous suture.

The retractor and intraperitoneal sponge-gauze are removed, and the intestines are restored to normal position. The abdomen is closed with each suture for the peritoneum, fascia, and skin.

\section{Tips and Warnings}

The author always tells the students, "When bleeding occurs, do not immediately stop the bleeding with panicking clamp or self-missing suture." Prompt clamp or suture tends to involve the neighboring organs, resulting in the postsurgical complications such as injury or fistula of the urinary tract or the intestinal tract. Therefore, first, push the gauze to the bleeding area, maintain transiently the hemostatic condition, and wait a little bit. During the wait, the operator can escape from the panicking time and will consider the most appropriate recovery. Small bleeding may stop and only the major bleeding remains. Sometimes, further dissection of surrounding tissues is needed along with keeping gauze pushing for the bleeding. Thus, the operator can easily find the bleeding point or vessels, and can perform the proper hemostasis using the pin-point clamp or suture without involving the neighboring organs. This is the most important for gynecologic surgeons treating the pelvic organs having many dilated vessels.

\section{Conflict of Interest}

None.

\section{References}

1 Konishi I. Basic procedure 2. In: Hiramatsu Y, Konishi I, Sakuragi $\mathrm{N}$, Takeda S, eds. Mastering the Essential Surgical Procedures OGS NOW, No.2 Total Abdominal Hysterectomy. Tokyo: Medical View; 2010:56-73

2 Koyama T, Togashi K, Konishi I, et al. MR imaging of endometrial stromal sarcoma: correlation with pathologic findings. AJR Am J Roentgenol 1999;173(03):767-772

3 Kido A, Togashi K, Koyama T, Yamaoka T, Fujiwara T, Fujii S. Diffusely enlarged uterus: evaluation with MR imaging. Radiographics 2003;23(06):1423-1439 